\title{
Implementasi Rencana Kerja Tahunan Sekolah Dasar di Era New Normal
}

\author{
Achmad Qhuzairy Qarasyi \\ Universitas Negeri Makassar \\ shasimay21@gmail.com \\ Sitti Habibah \\ Universitas Negeri Makassar \\ habibah.jhr@gmail.com \\ Sumarlin Mus \\ Universitas Negeri Makassar \\ sumarlin.mus@gmail.com
}

\begin{abstract}
The purpose of this research is to find out the lecturers' strategies in e-learning management to improve learning outcomes in college. The lecturer strategy in managing e-learning includes how to plan, implement, supervise and evaluate online learning (e-learning). This research used a qualitative approach with descriptive methods. The subjects of the study were lecturers who did online learning and were able to improve the results of learning through elearning. The research instrument used interview guidelines and documentation. Interview, survey, and observation were done to collect the data. Data analysis done by using triangulation techniques. The results of this study shows that the lecturer's strategy in managing e-learning, including 1) Planning, namely drawing up a learning plan on the elearning website, with a sub-view of RPS (lesson plan), learning achievements, diagnostic tests (pre-test), module materials, learning videos, journal links related to materials, discussion forums, tasks, and absorption tests (posttest).2) Execution, focus on how to solve material problem (reward and punishment) by understanding modules and videos. 3) Supervision is by utilizing the agreed e-learning time, monitoring process through zoom media, video conference and whatsapp group to know the students' participation in elearning. 4) Evaluation, with diagnostic tests and absorption tests as an indicator of student atteanity in receiving e-learning materials and independent tasks to improve HOTS (higher order of thinking skills) students. Evaluation in maximizing e-learning content in the website is done with CIPP (context, input, process, and output) so that innovation from lecturers is always increasing.
\end{abstract}

Keywords: Lecturers, E-Learning, Management, Universities, Strategy

\section{Article Info}

Received date: 26 April 2021

Revised date: 4 Mei 2021

Accepted date: 21 Juni 2021

\section{PENDAHULUAN}

Peraturan Menteri Pendidikan Dan Kebudayan Nomor 28 Tahun 2016 Tentang 110
Sistem Penjaminan Mutu Pendidikan Dasar Dan Menengah. Permendiknas Nomor 19 Tahun 2007 Tentang Standar Pengelolaan Oleh 
Implementasi Rencana Kerja Tahunan Sekolah Dasar di Era New Normal | Achmad Q. Qarasyi, dkk.

Satuan Pendidikan, sekolah membuat Rencana Kerja Jangka Menengah (RKJM) 4 tahun, Rencana Kerja Tahunan (RKT) dinyatakan dalam Rencana Kegiatan dan Anggaran Sekolah/Madrasah (RKAS/M) dilaksanakan berdasarkan RKJM. RKJM/T disetujui rapat dewan pendidik setelah memperhatikan pertimbangan dari Komite Sekolah dan disahkan berlakunya oleh Dinas Pendidikan Kab/Kota. Wabah corona merubah banyak hal, kebiasaan, perilaku, dan berbagai macam hal lainya termasuk di dalam dunia pendidikan. Untuk mengantisipasi itu semua terutama dalam bidang pendidikan, tentu saja diharapkan para tenaga pengajar seperti khususnya guru dapat tetap aktif melakukan kegiatan belajar walau tanpa tatap muka serta tetap bisa memotivasi para peserta didik.

Wabah corona merubah banyak hal, kebiasaan, perilaku, dan berbagai macam hal lainya termasuk di dalam dunia pendidikan. Untuk mengantisipasi itu semua terutama dalam bidang pendidikan, tentu saja diharapkan para tenaga pengajar seperti khususnya guru dapat tetap aktif melakukan kegiatan belajar walau tanpa tatap muka, serta tetap bisa memotivasi para peserta didiknya. Jika di era normal, biasanya proses belajar mengajar. Dilakukan secara tatap muka, maka di era covid seperti sekarang, proses tersebut hanya bisa dilakukan dengan tatap layar atau secara online

Implementasi atau pelaksanaan rencana kerja tahunan sekolah menjadi fokus utama dalam penelitian ini karena dapat mempengaruhi mutu sekolah, dan proses pendidikan melalui manajemen kepala sekolah dan guru. Oleh karena itu kemampuan kepala sekolah dalam mengelola SDM, sarana dan prasarana, sumber dana dan melakukan terobosan serta membangun jaringan yang mendukung proses pendidikan di sekolah menjadi faktor penentu pelaksanaan rencana kerja tahunan sekolah. Kepuasan guru, tenaga kependidikan, dan orang tua siswa merupakan salah satu indikator kualitas capaian rencana kerja tahunan sekolah, karena kepuasan tersebut akan menguatkan mutu kinerja sekolah. Berdasarkan hasil penelitian terdahulu dan hasil wawancara serta observasi peneliti mengenai kondisi sekolah, peneliti tertarik untuk melihat perubahan apa yang dilakukan oleh kepala sekolah khususnya pada implementasi rencana kerja tahunan sekolah di SDN Inpres Tetebatu di era New Normal yang berlokasi di Kecamatan Pallangga Kabupaten Gowa. Dimana rencana kerja tahunan sekolah (RKT) memberikan informasi tentang program kerja sekolah yang dibuat oleh kepala sekolah dan tim dalam mengelola segala sumberdaya yang ada di sekolah dengan cara yang terbaik, efektif dan efisien, untuk memberikan pelayanan yang berkualitas bagi peserta didik. Oleh karena itu kepala sekolah dituntut untuk selalu mampu mengelola sumber daya yang ada secara optimal.

Perencanaan pendidikan adalah kegiatan yang berkaitan dengan usaha merumuskan program pendidikan yang di dalamnya memuat segala sesuatu yang akan dilaksanakan, penentuan tujuan pendidikan, kebijakan dalam pendidikan, arah yang akan ditempuh dalam kegiatan pendidikan, prosedur dan metode yang akan diikuti dalam usaha pencapaian tujuan pendidikan. Guruge (1972) "Perencanaan pendidikan merupakan proses mempersiapkan kegiatan di masa depan dalam bidang pembangunan pendidikan. Dapat diurakan bahwa perencanaan pendidikan merupakan suatu proses kegiatan awal dari kegiatan pengambilan keputusan pendidikan dalam rangka pelaksanaannya sehingga memperoleh hasil proses yang telah disiapkan pada kegiatan dalam bidang pendidikan.

Peraturan Menteri Pendidikan Nasional Nomor 19 Tahun 2007, menempatkan penyusun program kerja atau RKS sebagai tahap awal dari seluruh aktivitas manajemen sekolah yang didahului dengan penenetapan visi, misi, dan tujuan sekolah. Peraturan tersebut juga mengamanatkan dilakukannya 
Evaluasi Diri Sekolah (EDS) sebagai salah satu dasar penyusunan program. Selain peraturan tentang Standar Pengelolaan, pemerintah juga menerbitkan Peraturan Menteri Pendidikan dan Kebudayan Nomor 28 Tahun 2016 Tentang Sistem Penjaminan Mutu Pendidikan Dasar dan Menengah (SPMP) yang memuat tentang penyusunan RKS dikaitkan dengan peningkatan dan penjaminan mutu sekolah.

Penyusunan RKS mengacu pada Undang-Undang Nomor 25 Tahun 2004 Tentang Sistem Perencanaan Pembangunan Nasional. UU Nomor 20 Tahun 2003 Tentang Sistem Pendidikan Nasional, Peraturan Pemerintah Nomor 19 Tahun 2005 Tentang Standar Nasional Pendidikan, yaitu Pasal 53 ayat (1) yang menyatakan bahwa setiap satuan pendidikan dikelola atas dasar rencana kerja tahunan yang merupakan penjabaran rinci dari rencana kerja jangka menengah satuan pendidikan yang meliputi masa 4 (empat) tahun. Peraturan Pemerintah Nomor 19 Tahun 2005 tentang Standar Nasional Pendidikan dijadikan landasan pengembangan satuan pendidikan. Standar nasional pendidikan antara lain Standar isi, Standar Proses, Standar Kompetensi Lulusan, Standar Pendidik dan Tenaga Kependidikan, Standar Sarana dan Prasana, Standar Pengelol aan. Standar Pembiayaan, dan Standar Penilaian. Hasil penelitian Mukhtar (2015, p. 1) menyebutkan bahwa melalui pendampingan manajerial secara kolaboratif kepala sekolah mampu menyusun RKS yang sesuai dengan kriteria yang ditentukan. Berliana (2014:1) hasil penelitiannya menyebutkan bahwa penyusunan rencana kerja tahunan sekolah sekolah meliputi: (1) analisis lingkungan strategis sekolah, (2) analisis situasi pendidikan sekolah saat ini, (3) analisis situasi pendidikan sekolah yang diharapkan 5 tahun kedepan, (4) identifikasi tantangan nyata antara pendidikan saat ini dengan pendidikan 5 tahun ke depan, (5) merumuskan visi dan misi sekolah, (6) merumuskan tujuan sekolah, (7) menentukan strategi penilaian/pencapaian, (8) menentukan rencana biaya (alokasi dana), dan (9) membuat monitoring dan evaluasi.

Berdasarkan uraian di atas penulis tertarik untuk meneliti tentang Implementasi Rencana Kerja Tahunan (RKT) Sekolah Dasar Tetebatu Inpres Kecamatan Pallangga Kabupaten Gowa pada Sekolah Era New Normal.

\section{METODE PENELITIAN}

Penelitian ini menggunakan pendekatan penelitian kualitatif dengan jenis penelitian studi kasus deskriptif. Waktu dan tempat penelitian di SDN Tetebatu Kecamatan Pallangga, merupakan salah satu sekolah Dasar di Kecamatan Pallangga Kabupaten Gowa. Sumber data dalam penelitian ini adalah, Pengawas, Kepala Sekolah, Guru dan tenaga kependidikan, serta orang tua siswa/komite yang memahami implementasi RKT di sekolah tersebut. Instrumen penelitian yang digunakan adalah observasi, wawancara, dokumentasi dan trianggulasi (Sugiyono, 2014). Teknik analisis data yang digunakan adalah mengacu pada konsep Milles dan Hubermen (1984) dalam Maleong (2019) yang mengklasifikasikan analisis data dalam empat langkah,antara lain tahap pengumpulan data tahap reduksi data. tahap penyajian data tahap penarikan kesimpulan dan verifikasi.

\section{HASIL DAN PEMBAHASAN}

Hasil penelitian berkenaan dengan implementasi rencana kerja tahunan sekolah selama New Normal di SD Inpres Tetebatu Kecamatan Pallangga Kabupaten Gowa yang diimplementasikan dalam bentuk program kegiatan berdasarkan hasil wawancara, dokumentasi dan observasi yang dilakukan oleh peneliti sebagai berikut:
a. Pelaksanaan Rencana Kerja Tahunan Sekolah Pada Kurikulum Dan Kegiatan Pembelajaran 
Implementasi Rencana Kerja Tahunan Sekolah Dasar di Era New Normal | Achmad Q. Qarasyi, dkk.

Berdasarkan hasil penelitian pada pelaksanaan rencana kerja tahunan sekolah pada pelaksanaan kurikulum dan kegiatan pembelajaran selama new normal dilakukan dengan menerapkan kurikulum 2013 melalui pembelajaran daring dan guru memahami pelaksanaannya dengan perangkat pembelajaran berupa silabus, RPP sesuai standar isi, kalender dan buku litaratur yang dapat mendukung pelaksanaan kurikulum dalam pembelajaran daring. Hasil penelitian ini diperkuat Undang-Undang RI Nomor 20 Tahun 2003 Tentang Sistem Pendidikan Nasional , menyebutkan bahwa "Kurikulum adalah seperangkat rencana dan pengaturan mengenai tujuan, isi, dan bahan pelajaran serta cara yang digunakan sebagai pedoman penyelenggaraan kegiatan pembelajaran untuk mencapai tujuan pendidikan tertentu". Kurikulum sejatinya dihadirkan supaya menjadi alat utama agar pendidikan dijalankan selaras dengan cita-cita bangsa.

\section{b. Pelaksanaan Rencana Kerja Tahunan Sekolah Pada Kesiswaan}

Berdasarkan hasil penelitian pelaksanaan rencana kerja tahunan sekolah pada program kesiswaan selama new normal tetap dilakukan, seperti penerimaan siswa baru dan penilaian tugas-tugas siswa dan ketepatan siswa dalam mengumpulkan tugasnya, serta ke aktifan siswa di dalam proses pembelajaran daring serta meningkatkan prestasi siswa melalui pembimbingan secara daring dan remedial tuntas berkelanjutan pada siswa yang memiliki prestasi baik dan tidak baik dan guru memberikan tutorial pembelajaran lewat video yang menjadi tugas siswa dan membimbing langsung melalui WA,. Hasil penelitian ini diperkuat Undang-UndangUndang RI Nomor 20 Tahun 2003 Tentang Sistem Pendidikan Nasional pada pasal 3 bahwa, "Pendidikan nasional berfungsi mengembangkan kemampuan dan membentuk watak serta peradaban bangsa yang bermartabat dalam rangka mencerdaskan kehidupan bangsa, bertujuan untuk berkembangnya siswa agar menjadi manusia yang beriman dan bertakwa kepada Tuhan Yang Maha Esa, berakhlak mulia, sehat, berilmu, cakap, kreatif, mandiri dan menjadi warga negara yang demokratis serta bertanggung jawab.

c. Pelaksanaan Rencana Kerja Tahunan Sekolah Pada Pendidik Dan Tenaga Kependidikan Serta Pengembangannya

Pelaksanaan rencana kerja tahun sekolah pada pendididk dan tenaga pendidik diperoleh data bahwa sekolah melakukan pengembangan pendidikan dan tenaga kependidikan melalui pelatihan. Peneliti menyimpulan bahwa, dalam Pelaksanaan Rencana Kerja Tahunan Sekolah Pada Pendidik Dan Tenaga Kependidikan yaitu dilakukan peningkatan komptensi bagi tenaga pendidik dan tenaga kependidikan di SDI Tetebatu di mana pelatihan terbesebut meliputu pelatihan Standar Pelayanan Minimal Internal untuk guru dan operator mengikutu pelatihan dapodik dan DIA sekolah untuk peningkatan komptensi tenaga pendidik dan tenaga kependidikan. Hasil penelitian ini diperkuat Peraturan Pemerintah No 19 Tahun 2017 Tentang Guru, bahwa" Guru adalah pendidik profesional dengan tugas utama mendidik, mengajar, membimbing, mengarahkan, melatih, menilai, dan mengevaluasi peserta didik pada pendidikan anak usia dini jalur pendidikan formal, pendidikan dasar, dan pendidikan menengah

\section{d. Pelaksanaan Rencana Kerja Tahunan Sekolah Pada Sarana Dan Prasarana}

Pelaksanaan rencana kerja tahunan sekolah pada sarana dan prasarana diperoleh data bahwa sekolah melakukan pengembangan pendidikan dan tenaga kependidikan. Berdasarkan hasil penelitian peneliti menyimpulkan bahwa pelaksanaan rencana kerja tahunan sekolah pada sarana 
dan prasarana sekolah di SDI Tetebatu dilakukan dengan melakukan pembangunan renovasi gedung sekolah antara lain ruangan guru dan toilet sekolah dalam meningkatkan mutu sarana prasarana sekolah. Hasil penelitian ini diperkuat Peraturan Pemerintah Nomor 19 Tahun 2005 Tentang Standar Nasional Pendidikan, pasal 42 dimana setiap satuan pendidikan wajib memiliki sarana yang meliputi perabot, peralatan pendidikan, media pendidikan, buku dan sumber belajar lainnya, bahan habis pakai, serta perlengkapan lain yang diperlukan untuk menunjang proses pembelajaran yang teratur dan berkelanjutan.

e. Pelaksanaan Rencana Kerja Tahunan Sekolah Pada Keuangan Dan
Pembiayaan

Pelaksanaan rencana kerja tahuanan sekolah pada keuangan dan pembiayan diperoleh data bahwa sekolah selalu melaksanakan rapat kerja dan menyusun program rencana kerja sekolah (RKJM/RKT dan RKAS) disusun berdasarkan Raport Mutu dan hasil Evaluasi Diri Sekolah (EDS) dan rekomendasi yang dihasilkan pada EDS. Berdasarkan dokumen Rencana Kerja Anggaran Sekolah tahun 2020 data penggunaan pembiayaan rencana kerja tahunan sekolah dianggarkan pada pembiayaan administrasi kegiatan Sekolah dilaksanakan pada triwulan pertama, kedua, ketiga, Hasil penelitian ini diperkuat Undang-Undang RI Nomor 20 Tahun 2003 Tentang Sistem Pendidikan Nasional, lebih lanjut telah mengatur beberapa pasal yang menjelaskan pendanaan pendidikan yaitu pada Pasal 11 Ayat 2 Pemerintah dan Pemerintah Daerah wajib menjamin tersedianya dana guna terselenggaranya pendidikan bagi setiap warga negara yang berusia tujuh sampai lima belas tahun

\section{f. Pelaksanaan Rencana Kerja Tahunan Sekolah Pada Budaya Dan Lingkungan Sekolah}

Hasil penelitiannya menunjukkan bahwa pelaksanaan rencana kerja tahunan sekolah pada pelaksanaan Budaya Dan Lingkungan Sekolah selama new normal tetap dilakukan oleh sekolah. Berdasarkan dari hasil wawancara peneliti pada pengawas, kepala sekolah, guru, orang tua/komite, operator serta hasil observasi dan dokumentasi dimana pelaksanaan rencana kerja tahunan sekolah pada budaya dan lingkungan Sekolah untuk kondisi di era new normal tidak lakukan di sekolah melainkan budaya dan lingkungan sekolah diimplementasikan di rumah masing-masing melalui pembiasaan disiplin positif waktu belajar daring dan pembiasaan bersih rumah. Hasil penelitian ini diperkuat oleh Deal dan Peterson dalam Supardi (2015) menyatakan bahwa: "Budaya sekolah adalah sekumpulan nilai yang melandasi perilaku, tradisi, kebiasaan keseharian, dan symbol-simbol yangdi praktekkan oleh kepala sekolah, guru, petugas administrasi, siswa dan masyarakat sekitar sekolah. Budaya sekolah merupakan ciri khas, karakter atau watak, dan citra sekolah tersebut di masyarakat luas"

\section{g. Pelaksanaan Rencana Kerja Tahunan Sekolah Pada Peran serta Masyarakat Dan Kemitraan}

Berdasarkan hasil penelitian didapatkan data bahwa pelaksanaan rencana kerja tahunan sekolah pada peran serta masyarakat dan kemitraan tidak ditemukan adanya kerjasama sekolah dengan pihal luar. Selama pembelajaran daring orang tua siswa diikutsertakan membantu guru dalam membimbing anaknya bersikap disiplin positif selama proses pembelajaran di rumah. Hasil penelitian ini diperkuat oleh oleh (Zaini, A., Zakso, A., \& Syukri, 2014). Penyelenggaraan pendidikan dilakukan 
Implementasi Rencana Kerja Tahunan Sekolah Dasar di Era New Normal | Achmad Q. Qarasyi, dkk.

tidak hanya oleh pihak sekolah, seperti pendidik dan tenaga kependidikan, namun keberadaan masyarakat dan orangtua peserta didik ikut mewujudkan pencapaian pendidikan yang lebih baik.

h. Pelaksanaan Rencana Kerja Tahunan Sekolah Pada Rencana-Rencana Kerja Lain Yang Mengarah Kepada Peningkatan Dan Pengembangan Mutu

Implementasi rencana kerja tahunan sekolah ini dimaksudkan agar dapat dipergunakan sebagai kerangka acuan oleh kepala sekolah dalam mengambil kebijakan, disamping itu sebagai pedoman dalam mencapai keberhasilan pelaksanaan progam belajar mengajar dan administrasi sekolah yang lain, agar pengelola sekolah tidak menyimpang dari prinsip-prinsip manajemen. Keberhasilan implementasi rencana kerja tahunan sekolah ini menuntut peran serta aktif dari seluruh warga sekolah dan dukungan dari warga masyarakat. Rencana kerja sekolah yang digunakan sebagai pedoman pengelolaan sekolah perlu mempertimbangkan visi, misi dan tujuan sekolah, serta ditinjau dan dirumuskan kembali secara berkala sesuai dengan perkembangan masyarakat. Hasil penelitian ini diperkuat dengan Permendiknas Nomor 63 Tahun 2009 Peraturan Menteri Pendidikan Nasional Tentang Sistem Penjaminan Mutu Pendidikan, adalah tingkat kecerdasan kehidupan bangsa yang dapat diraih dari penerapan sistem pendidikan nasional.

\section{KESIMPUALAN}

Implementasi rencana kerja tahunan sekolah di era New Normal di Sekolah Dasar Inpres Tetebatu Kecamatan Pallangga Kabupaten Gowa dapat simpulkan sebagai berikut: Implementasi atau pelaksanaan rencana kerja tahunan selama era new normal yang mengalami perubahan pelaksanaanya adalah (a) kurikulum dan kegiatan pembelajaran melalui luring menjadi daring, (b) pelaksanaan pengadaan sarana dan prasarana dengan melakukan renovasi ruang guru dan toilet sekolah untuk, (c) pelaksanaan keuangan dan pembiayaan; penggunaan dengan pembelian kuota belajar daring untuk guru dan siswa, (d) pelaksaksanaan budaya dan lingkungan sekolah; di sekolah dilakukan di rumah masing-masing, melalui disiplin positif dalam pembelajaran daring, pelaksanaan RKT tidak mengalami perubahan adalah: (a) kesiswaan, (b) pendidik dan tenaga kependidikan tetap dilaksanakan seperti tahun sebelumnya, dan yang tidak terlasana pada era new normal adalah: (a) peran serta masyarakat dan kemitraan,serta (b) rencana-rencana kerja lain yang mengarah kepada peningkatan dan pengembangan mutu, sehingga capaian rencana kerja tahunan sekolah belum sesuai dengan Permendiknas Nomor 19 Tahun 2007 Tentang Standar Pengelolaan Oleh Satuan Pendidikan. Adapun saran untuk peneliti kedepannya bahwa kajian ruang lingkup studi ini difokuskan pada implementasi rencana kerja tahunan sekolah di masa era new normal. Keterbatasan ini mengisyaratkan perlunya studi lanjutan untuk menggeneralisasi hasil-hasil yang diperoleh pada konteks yang berbeda dan lebih luas, sehingga konsep-konsep yang didapatkan dapat ditingkatkan pengelolaan mutu sekolah.

\section{DAFTAR PUSTAKA}

Guruge. (1972). Educational Planing.

Moleong, L. J. (2019). Metodologi Penelitian Kualitatif. PT Remaja Rosdakarya.

Mukhtar, R. (2015). Rencana Pengembangan Sekolah. Jurnal Manajer Pendidikan, 9(3).

Peraturan Menteri Pendidikan dan Kebudayan Nomor 28 Tahun 2016 tentang Sistem Penjaminan Mutu Pendidikan Dasar dan Menengah.

Peraturan Menteri Pendidikan Nasional Nomor 19 Tahun 2007. 
Peraturan Pemerintah No 19 Tahun 2017 tentang Guru. (n.d.).

Peraturan Pemerintah Nomor 19 Tahun 2005 tentang Standar Nasional Pendidikan. (n.d.).

Permendiknas Nomor 19 Tahun 2007 tentang Standar Pengelolaan oleh Satuan Pendidikan.

Permendiknas nomor 63 tahun 2009 peraturan menteri pendidikan nasional tentang sistem penjaminan mutu pendidikan. (n.d.).

Sugiyono. (2014). MetodePenelitian Manajemen. Alfabeta.
Supardi. (2015). Sekolah Efektif: Konsep Dasar dan Prakteknya. Rajawali.

Undang-undang Nomor 25 Tahun 2004 tentang Sistem Perencanaan Pembangunan Nasional.

Undang-undang RI nomor 20 Tahun 2003 tentang Sistem Pendidikan Nasional. (n.d.).

UU Nomor 20 Tahun 2003 tentang Sistem Pendidikan Nasional.

Zaini, A., Zakso, A., \& Syukri, M. (2014). Partisipasi Masyarakat Dalam Penyelenggaraan Pendidikan. Jurnal Pendidikan Dan Pembelajaran, 3(11), $1-13$. 